\title{
EDUCAÇÃO CONTINUADA EM ENFERMAGEM DE SAÚDE PÚBLICA
}

Marie Azuma Rodrigues*

RODRIGUES, M. A. Educação continuada em enfermagem de saúde pública. Rev. Esc. Enf. USP, São Paulo, 18(2):129-140, 1984.

Este artigo aborda os aspectos teórioss da educasão continuada, a saber: conceitos, caracteristicas, relação que existe com a educaşão de adultos $e$ as modalidades de métodos e técnicas. Também destaca alguns pontos significativos da educaçāo continuada em enfermagem de saúde pública.

\section{INTRODUÇÃO}

Para operacionalizar um projeto inovador na área de Saúde, é essencial a formação de recursos humanos. Embora isto seja uma questão de investimento maior no momento de contenção de gastos, a médio e a longo prazo, será uma medida de economia. Em programas de extensão de cobertura dos serviços de saúde, a "educação em serviço" proporcionada, de modo crítico e construtivo, para o pessoal de nível primário, constitui o elemento fundamental para a transformação dos serviços de saúde. Se isto não for proporcionado de maneira adequada, a assistência permanecerá a mesma e o plano será desmoralizado.

Quanto aos profissionais, a educação em nível de graduação não oferece suficientes oportunidades de aprendizagem ${ }^{5}$. Por outro lado a revolução científico-técnica modifica, em curtos períodos de tempo, tanto os conceitos que se adquirem durante a formação básica como a tecnologia que apoia $e$ complementa 0 trabalho do pessoal da equipe de saúde ${ }^{7}$. Assim, a necessidade de manter atualizado o pessoal de saúde tornase evidente, ao mesmo tempo que se torna necessária mudança no conteúdo da educação, que não pode mais, mesmo no quadro estritamente profissional, restringir-se aos conhecimentos práticos puramente utilitários que serão ultrapassados rapidamente; deve ela permitir a cada um adquirir aptidóes que facilitariam ada ptaçōes ${ }^{1}$ às circunstâncias.

Uma situação encontrada, muitas vezes, no sistema de saúde é o mau uso e inadequada distribuição do pessoal de assistência à saúde. Quando é

Enfermeira. Auxiliar de Ensino do Departamento de Prática de Saúde Pública da Faculdade de Saúde Pública da USP. 
verificada deficiência de elementos qualificados para desempenharem funções necessárias à assistência, são os mesmos substituídos por pessoas de qualificação acima ou abaixo da necessária para o exercício da atividade, resultando, quase sempre em baixa produtividade no trabalho ${ }^{3}$ e insatisfação do trabalhador, que não realiza funções no nível de suas habilidades nem de sua educação.

Para proporcionar educação em serviço de forma contínua, visando a transformação, atualização do pessoal profissional e saneamento dos problemas surgidos das relações educação-emprego, propōe-se "maior extensão do processo educativo que consiste na integração entre o sistema educacional e o sistema de treinamento para $o$ trabalho e que foi denominado sistema de educação continuada ${ }^{3}$.

A atualização de conhecimentos durante toda a vida profissional constitui um complemento indispensável da graduação, e é nesta educação que as pessoas encontram a motivação necessária para desenvolverem conduta criativa de adaptação às novas exigências ${ }^{1}$. A educação continuada, além de aumentar a eficiência da organização, aumenta a satisfação dos agentes no trabalho e deve ser considerada um elemento essencial no progresso da carreira a ser oferecido a cada trabalhador individual como um direito básico ${ }^{4}$.

A educação continuada é um meio de aprendizagem sistematizada do trabalhador e é uma responsabilidade compartilhada do próprio individuo, da ação planejada do sistema de saúde, do sistema de educação e das associaçôes profissionais.

A UNESCO, em sua 14ạ Conferência Geral (1966-Paris) considerou prioritária a educação permanente ou educação continuada ${ }^{3}$. A XIX Conferência Sanitária Panamericana (1974) destacou a importância da educação continuada para apoias e aumentar a competência do profissional de saúde ${ }^{8}$. O programa a médio prazo da OMS, para o Desenvolvimento dos Recursos Humanos em Saúde - 1984-89 tem como meta desenvolver sistema adequado de educação continuada, incluindo sua integração com a supervisão em todos os niveis ${ }^{4}$.

\section{CONCEITOS}

Entre os conceitos encontrados na literatura específica sobre educação continuada podem ser destacados os seguintes:

"Educação continuada de profissionais de saúde é c processo que inclui as experiencias posteriores ao adestramento inicial, que ajudam o pessoal de assisténcia à saúde a aprender competências importantes para o seu trabalho. A educação continuada adequada deveria refletir as necessidades de saúde da comunidade e conduzir a melhoria planejada da saúde da comunidade" (OMS, 1982). 
"Educação continuada é um processo que deve continuar durante a vida adulta" (14ạ Conferência Geral da UNESCO - Paris/66).

"Educação continuada é um processo de ensino e aprendizado ativo e permanente que se inicia após a formação básica e está destinado a atualizar e melhorar a capacidade de uma pessoa ou grupo, frente às evoluções técnico-científica e às necessidades sociais" (Grupo de peritos da OPAS).

"Educação continuada é um processo que o profissional deve realizar de forma permanente e sistematizada para obter novos conhecimentos, avaliar a validade dos anteriormente adquiridos e compensar suas carências de maneira a que o desempenho de seus trabalhos resulte na máxima eficiência para a sociedade" (PEREDA ${ }^{6}$ ).

TORRE MONTEJO et alii ${ }^{8}$ concebem a educação continuada como um processo permanente de aprendizagem que se inicia no momento em que o profissional ou técnico termina seu curso de formação básica ou de especialização, para jamais abandoná-la durante todo o tempo que permaneça no exercício profissional.

Complementando o conceito acima, PEREDA 6 escreve que a educação continuada é um processo intencional, formalizado ou não pelo ensino, que consiste em adquirir, incrementar e manter atualizados os conhecimentos, habilidades e atitudes que permitam enfrentar e resolver corretamente os problemas de proporcionar serviços eficientes e eficazes.

A OMS $^{4}$ exclui da educação continuada os cursos de pós-graduação que conduzem a qualificaçōes específicas, embora concorde que a decisáo é arbitrária, baseando-se no fato de que a pós-graduação tem mais em comum com o adestramento inicial.

Considera, porém, que pode não existir distinção entre adestramento inicial e educação continuada e que o limite entre estes não deve ser rígido. Dá ênfase ao fato de que todo o pessoal de saúde deve estar incluído, desde os profissionais até os agentes de saúde da comunidade, e que a educação deve estar orientada para o desenvolvimento de competências que reforcem algum aspecto de assistência à saúde.

BASTOS $^{\mathfrak{1}}$, analisando alguns autores, diz que a educação continuada "para uns, é usada como sinônimo de pós-graduação; para outros se refere a qualquer educação após o término de um programa básico, incluindo treinamento em especialidade. $\dot{E}$ considerada como uma educação complementar, ou seja, que deve dar ao profissional aquilo que ele não teve no curso acadêmico; é algo que acrescenta a este. Outras vezes é considerada como educação prolongada, isto é, aquela que se estende além dos anos escolares obrigatórios. As vezes, é considerada como treinamento periódico de 'refrescamento' para manter o profissional atualizado em seus conhecimentos". 
KURCGANT ${ }^{3}$, analisando a relação educação continuada e educação em serviço, relata que alguns autores incluem educação continuada na educação em serviço, outros as confundem e outros consideram-na mais abrangente, incluindo nela a educação em serviço. "Para a American Nursing Association - ANA -, a educação em serviço é um programa de instrução ou treinamento, proporcionado pela instituição empregatícia, em uma área específica da prática. Educação continuada inclui educação em serviço, mas exclui orientação em serviço, que é considerado como preparação para uma posição específica". Resumindo ainda outras opiniðes, escreve que "a educação em serviço é destinada a destnvolver o indivíduo em assuntos específicos de seu trabalho, sendo realizada dentro da instituição empregatícia e a educação contínua pode utilizar recursos fora do trabalho e visa ao desenvolvimento profissional e pessoal do indivíduo... A ANA, que estuda o assunto desde 1952, define educação continua num sentido mais amplo e em determinado campo de ação, como toda educação além de formação inicial. Num sentido restrito, entretanto, esse termo pode ser usado para programas organizados e formais, estudos independentes e informais e cursos oferecidos por escolas e faculdades".

\section{CARACTERISTICAS DA EDUCAÇĀO CONTINUADA}

Segundo a $\mathrm{OMS}^{5}$, a educação continuada é vista como uma parte do sistema administrativo ou do processo administrativo. Uma administração efetiva inclui a educação continuada para recursos humanos e, sob o ponto de vista administrativo, isto é importante por duas razões: como uma forma de manter os modelos de prestação de assistência à saúde e como uma parte essencial do processo de introduzir qualquer mudança nos métodos de trabalho de saúde, representando os meios pelos quais o pessoal de saúde aprende novas técnicas, abordagens e atitudes. Portanto educação continuada constitui preocupação não somente para as instituições educacionais e programadores de formação, como também para aqueles que empregam os profissionais de saúde.

Um sistema adequado de educaçâo continuada, segundo a $\mathrm{OMS}^{4}$, apresenta as seguintes caracteristicas:

a) universalidade: deve ministrar educação a todos os membros de cada categoria de pessoal de saúde, como por exemplo, sem impedimento de acessibilidade geográfica;

b) baseado na análise das necessidades: a educaçâo deve estar orientada para o trabalho ou tarefa e ser pertinente às necessidades da comunidade;

c) continuidade: deve ministrar educação seqüencial e progressiva durante toda a carreira do trabalhador deixando de ser esporádica e ocasional; 
d) coordenação interna: deve estimular as instituições educacionais para cooperar com os serviços, compartilhando recursos e ministrando programas educacionais complementares;

e) relacionando com outros sistemas: deve estar estritamente relacionado com o sistema de prestação de serviços de saúde como um todo e com o sistema de formação de recursos humanos de saúde em particular.

BASTOS $^{1}$, ao analisar os tipos de estruturas nas quais se processa a educação continuada, relata que, em alguns países, a educação continuada não obedece a qualquer sistema e se desenvolve de maneira absolutamente independente, ao passo que, em outras, forma um sistema autônomo paralelo aos órgãos oficiais do setor de educação, sem conexão ou entendimento com eles. Segundo o autor, pelo conceito, ela deve ser inclurda no planejamento geral do sistema de educação do país e converter-se em uma parte integrada dos sistemas nacionais de educação e saúde, deixando de ser uma atividade marginal ou ocasional.

A OMS, através da resolução aprovada na vigésima sétima Assembléia Mundial de Saúde (1974), recomenda aos Estados Membros, a criação de sistemas nacionais de formação permanente para os membros das profissões sanitárias e que estes sistemas estejam integrados com os sistemas de ação sanitária e de educação, sendo os recursos universitários e das escolas de ciências de saúde plenamente utilizados. Na União Soviética, o Ministério da Saúde e o Ministério da Educação executam programas de educação continuada sob a coordenação do Instituto Central para Estudos Médicos Avançados, que serve de centro educacional e metodológico. Nos Estados Unidos, a educação continuada dos médicos é um dos objetivos permanentes da Associação Médica Americana. Na França, a Confederação dos Sindicatos Médicos Franceses e a Federação dos Médicos da França criaram a Associaça Nacional para a Formação Médica Contínua. Em Bruxelas, as escolas de Medicina, em associação com a Sociedade Cientifica de Medicina Geral, organizam cursos e seminários com a colaboração da Rádio Televisão de Bruxelas. Em nivel internacional existe o Sistema Internacional de Educação Continuada, com sede na França.

\section{EDUCAÇÃO CONTINUADA E EDUCAÇÃO DOS ADULTOS}

Vários autores concordam em que a educação continuada é destinada aos adultos e estes constituem um grupo especifico, por contarem com conhecimentos, vivência e experiências profissionais, que os diferenciam dos adolescentes; os seus mecanismos mentais - percepção, interpretação, memória - e sua psicologia - interesses e motivaçôes - são diferentes ${ }^{5}$.

A educação para adultos não pode ser uma tarefa individual e assistemática; deve ser uma aprendizagem sistemática e dirigida.

A educação de adultos foi definida, na Conferência Internacional sobre 
Educação de Adultos (1972), como o "processo pelo qual as pessoas que não freqüentam mais estabelecimentos escolares e em tempo integral - salvo quando se trata de grupos de educação de adultos - entregam-se a atividades seguidas e regulares com a intenção de melhorar suas informações, conhecimentos, competência, comportamento, julgamento ou para delimitar e resolver problemas"3.

$\mathrm{Na}$ educação continuada devem ser analisadas as características de ordem psicológica, social e cultural dos grupos de adultos e utilizados métodos, técnicas e procedimentos que correspondam àquelas características ${ }^{1}$.

A seguir, resumem-se alguns aspectos significativos que ESCOBAR ${ }^{2}$ relata no seu texto.

A educação continuada proporciona um tipo de aprendizagem que acrescenta novos conhecimentos aos de um adulto ou pessoa supostamente madura, os quais mudem suas atitudes e opiniōes, estendam suas perspectivas ou alterem sua conduta.

A inabilidade pdra aprender por motivos diretamente relacionados com a idade poucas vezes se apresenta. Em relação à quantidade de aprendizagem são pequenas em comparação com as diferenças entre grupos de diferentes idades.

$O$ estudante jovem e o adulto têm problemas diferentes a resolver, diferem fisiologicamente e em experiências e este já tem a sua personalidade desenvolvida. As diferenças psicológicas demandam um enfoque diferente do processo ensino-apren dizagem.

a) Modalidades de conduta. $\mathrm{O}$ adulto, com personalidade mais definida $\mathrm{e}$ rigida, é mais difícil de se ajustar a ambientes socialmente diferentes; tem maior tendência em manter-se dentro de padrōes estabelecidos; torna-se inquieto perante as idéias e experiências novas, que entram em conflito com o costume de manutenção do "status quo"; preferem programas que ensinem o que já sabem e que fortifiquem sua posição atual.

b) Atitude em relação ao tempo. Para o adulto o tempo é limitado e progressivamente mais curto; tem o temor constante de perder tempo que considera irrecuperável e finito.

c) Experiência. $\mathrm{O}$ adulto possui maior quantidade de experiências, que são diferentes em qualidade e que contribuem, na situação, para a aprendizagem.

d) Motivação. O adulto deseja conhecer algo que possa utilizar de alguma forma, tem aprendido a necessidade de ser paciente, é constante em conseqüência sua margem de atenção é mais extensa.

e) Relação professor-estudante. $\mathrm{O}$ adulto crê saber mais do que na realidade 
sabe e se sente ameaçado na situação de aprendizagem; não considera o professor como uma autoridade; tem lógica, personalidade e base própria; é fácil que surjam problemas de comunicação.

f) Objetivos de aprendizagem. O motivo pelo qual um adulto participa de um programa de educação é complexo; com maior freqüência encontrase como motivos, o reconhecimento do valor positivo da educação na solução de problemas e de sua possível relação com a felicidade e êxito.

Considerando as diferenças entre as teorias de aprendizagem e aquelas próprias do estudante adulto, é possível assinalar alguns princípios básicos para um programa de educaçđo continuada, a saber:

a) a aprendizagem do adulto deve estar centrada em problemas especificos; não deve haver lapso entre a educação e a aplicação prática do conteúdo; deve ser feito um levantamento dos problemas para que sejam determinadas as prioridades de seu estudo e análise; a motivação deve ser intrinseca; o estudante deve participar no desenvolvimento de sua própria experiência de aprendizagem, determinando suas necessidades e possibilidades de satisfazê-las;

b) a aprendizagem deve estar baseada na experiência; deve prover experiências relacionadas com os problemas do aluno; o estudante aprenderá melhor se a situação apresentar maior interesse e estiver mais próxima da sua própria experiência;

c) o estudante deve compartilhar com o professor da responsabilidade de criar um clima onde se aprecie o significado da experiência, o qual não chegará passivamente ao estudante sem sua participação;

d) o estudante deve ter a oportunidade de examinar e avaliar a sua experiência;

e) os propósitos da aprendizagem devem ser estabelecidos por escrito e a busca de soluçoes deve ser organizada pelo estudante; o estudante ativo aprende de maneira mais efetiva que o passivo;

f) os estudantes devem ter informação sobre o seu progresso até os objetivos pré-determinados; os docentes devem proporcionar indicaçoes dos êxitos ou fracassos e a adequação da experiência para seus problemas especfficos.

"O adulto deseja aprender mas raramente admite isto e quer melhorar porque às vezes percebe uma discrépância entre o que quer ser e o que é. Em decorrência da ambivalência e do conflito em geral, os adultos mostram alguma resistência à mudança e menos curiosidade pelas coisas novas, além de temores e inseguranças" 2 .

A OMS $^{5}$ recomenda a utilização, na programação de educação continua- 
da, de métodos pedagógicos não diretivos, grande flexibilidade ao nível de execução e aplicação de alguns princípios, tais como:

a) fazer os educandos participarem em todas as etapas da educação, planejamento, preparação, realização e avaliação;

b) fazer os educandos expressarem as necessidades e deixar que evoluam, permitindo diferentes caminhos e ritmo individual;

c) deixar a progressão sob a decisão do indivíduo ou do grupo, não só quanto ao ritmo, como quanto à orientação da progressão;

d) favorecer a educação mútua entre os educandos, estimulando as decisð̄es e outras formas de comunicaçðo horizontal;

e) considerar a avaliação - individual e grupal - como o ato educativo por excelência, gerador de novos temas e orientações.

\section{TIPOS E FORMAS DE EDUCAÇĀO CONTINUADA} níveis:

Segundo os objetivos, a educação continuada pode se processar em vários

a) capacitação ou superação - em que uma pessoa siga um programa de estudo formal bem articulado para elevar seu nível de educação;

b) atualização - em que uma pessoa que tenha recebido o grau acadêmico há dez ou mais anos, possa seguir programas que lhe permitam situar seu grau de conhecimentos a um nível comparável ao de um recém-graduado;

c) diversificação - em çue uma pessoa formada em certa área possa aspirar a obter certa educação formal em outra área, sem ter que recorrer necessariamente a um grau superior, e

d) ampliação de espectro - em que uma pessoa possa ampliar suas perspectivas, inclusive nos aspectos financeiros, politicos e sociais, sem ter necessariamente que elevar o nível acadêmico de sua educação, isto é, sem ter que optar por um grau superior.

A educação continuada, para capacitar, tem, como objetivo fundamental, que o individuo adquira habilidades a fim de realizar com maior eficiência as tarefas atribuídas ao pessoal; para atualizar, tem, como meta, ampliar a base dos conhecimentos, permitindo-lhe familiarizar-se com um caudal de informação sobre os últimos avanços, a fim de trabalhar com maior eficiência. Há maior diversificação aos estratos administrativos e diretivos mais altos da organização, permitindo ao profissional em geral situar-se na intrincada problemática do mundo contemporâneo ${ }^{6}$.

Segundo vários autores ${ }^{1,2,5,6,8}$, as formas de educação continuada podem ser programas organizados e formais, estudos independentes e informais, cursos oferecidos dentro ou fora de escolas e universidades; devem reconhe- 
cer a possibilidade de outras instituiçōes e pessoas, além do professor, exercerem funçð̃es educativas. Os tipos de atividades estão em correspondência com os objetivos de cada um deles; em geral, dado o seu caráter intensivo e de curta duração, têm a perspectiva de cursos formais de especialização.

Relacionam-se a seguir algumas dessas formas:

- auto estudo ou auto instrução ativos, contatos profissionais, participação em reuniões cientf́ficas e técnicas, estágios, visitas, consultas a bibliotecas;

- conferências, mesas redondas, painéis, ciclos de conferências;

- seminários especializados, simpósios, jornadas, reuniōes;

- cursos por correspondência, palestras, estudos dirigidos, demonstraçðes, discussoes em grupo;

- cursos curtos, de perfodo integral, orientados para a atualização de conhecimentos;

- cursos de duração média, orientados para aprofundar conhecimentos em aspectos concretos da especialidade;

- cursos mais longos, de um ano, por exemplo, para desenvolvimento de conhecimentos e habilidades sobre técnicas;

- cursos altamente especializados;

- treinamentos individuais, com ênfase no aspecto prático, com duração variando de algumas semanas a meses, de acordo com programas específicos, etc.

\section{EDUCAÇÃO CONTINUADA E ENFERMAGEM DE SAÚDE PÚBLICA}

Segundo BASTOS ${ }^{1}$, a educação continuada é uma necessidade vital e uma obrigação moral para o profissional de qualquer área. Relata o autor que, em alguns países, já é exigida, periodicamente, a renovação do certificado de licença, limitada por algum tempo, para o indivíduo poder continuar no exercício de algumas profissðes; acentua, ainda, que o profissional ou cada grupo de profíssionais, deve ter direito à educação e desempenhar o dever de ministrar educação, assumindo alternadamente as funçðes de educador e educando numa situação de educação continuada.

O campo de medicina, pela sua natureza, parece que é onde se tem adquirido maior experiência em educação continuada.

O Guia para organização de programas de educação continuada para o pessoal de saúde, editada pela OPAS, em $1978^{\circ}$, e Continuando a educação 
dos trabalhadores de saúde, da OMS, de $1982^{4}$, constituem boas referências para a organização de programas de educação continuada, destinados ao conjunto do pessoal de saúde, nas atividades de extensão de cobertura dos serviços de saúde a toda a população.

Tradicionalmente, as atividades de educação continuada, em outras áreas, têm sido de caráter marginal e têm-se dirigido, principalmente, para a atualização dos profissionais; o treinamento do pessoal auxiliar não tem sido enfatizado. Este fato não ocorreu na área de enfermagem, pois o treinamento do pessoal auxiliar sempre fez parte das funçбes do profissional de enfermagem.

No entanto, a ênfase dada à educação continuada pelos organismos internacionais tem-se refletido, também, na enfermagem. Atualmente, a preocupação dos profissionais tem aumentado em relação a esse assunto, fato que pode ser justificado, provavelmente, pelos fatores abaixo relacionados.

$\mathrm{Na}$ enfermagem, no Brasil, quantitativamente, o pedomínio é do grupo menos qualificado, isto é, o de atendentes. E destes que depende, em boa parte, o funcionamento diário dos serviços de saúde e a qualidade da assistência de enfermagem prestada; por esse grupo o enfermeiro é responsável, sendo exigido do mesmo constante processo de atualizaçđ̃o.

A expressão do grupo de enfermagem é demonstrada por SANTOS \& VIEIRA $^{7}$ que, em 1974, apresentaram a seguinte proporçð̃o de pessoal de enfermagem nos serviços de saúde pública:

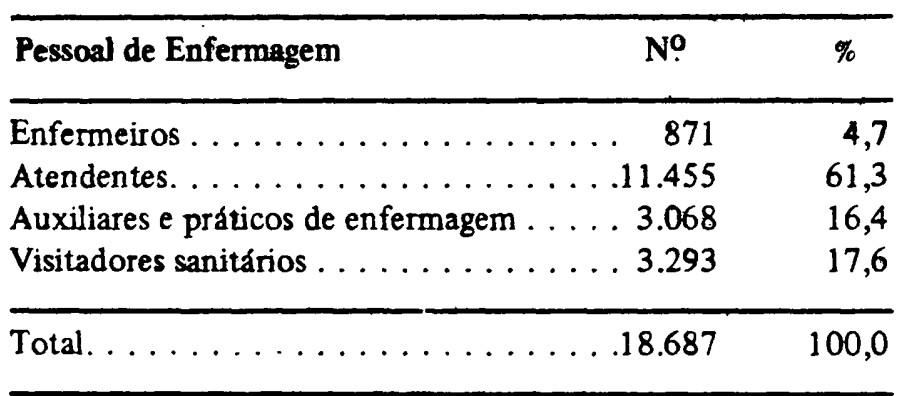

A tendência desta proporcionalidade se acentuar parece ser maior, quando se consideram os programas de extensáo da cobertura dos serviços de saude, que adota a estratégia de utilizar maior número de pessoal auxiliar para estender a cobertura das açôes de saúde à população. Torna-se, assim, evidente o aumento da responsabilidade do enfermeiro em participar na provisão de educação continuada desse pessoal.

Um outro fator relaciona-se com a educação continuada do próprio profissional de enfermagem. 
O desenvolvimento tecnológico e cientifico é cada vez mais acelerado e, entre o aparecimento, difusão e a assimilação do conhecimento, o espaço de tempo é cada vez menor. Com a crise do sistema de prestação da assistência à saúde, até então em vigor, surgem conceitos novos, idéias e experiências inovadoras que são divulgadas, questionadas e até invalidadas ou superadas rapidamente. Para assimilar criticamente estas informaçôes e exercer as funçס̄es cada vez mais complexas e diversificadas, o enfermeiro não pode mais depender, somente, das bases de conhecimentos adquiridos no curso superior e dos conhecimentos decorrentes das experiências acumuladas no exercício profissional.

Por meio da educação continuada é que os enfermeiros vão "entender o significado dos novos conceitos e seu papel face a eles" e ter a fundamentação para "participar das açð̄es políticas visando à luta pela manutenção e ampliação do espaço ocupado pela enfermeira na estrutura ocupacional dos serviços de saúde"

O profissional pode se tornar marginalizado não só pela ignorância dos avanços da ciência ou da sua prática, como também pelo "esquecimento" dos conhecimentos já adquiridos através da educação ou da experiência profissional. Segundo alguns autores, a taxa de esquecimento é tão alta que anos e até meses depois da graduaçăo, muito do conteúdo do currículo, se tiver que ser aplicado, tem que se reaprendido.

RODRIGUES, M. A. Continued education in public health nursing. Rev. Esc. Enf. USP, Săo Paulo, $18(2): 129-140,1984$.

This paper deals with the theoretical aspects of continued education: concepts, characteristics and relationship to adult education, as well as modalities of methods and technics. It also emphasizes some significant aspects of continued ectucation in public health nursing.

\section{REFERÊNCIAS BIBLIOGRÁFICAS}

1. BASTOS, N. C. de B. A educaço contínua mas profissōes de saúde. Rev. Fund. SESP, Rio de Janeiro, 23(2): 31-37, 1978.

2. ESCOBAR, F. Princípios del apreadizaje del adulto em programas de educación continua. Educ. Méd. Salud, Washington, 12(2): 134-147, 1978.

3. KURCGANT, P. Educaf̧ão contínua: necessidades sentidas e evidenciadas por enfermeiros e obstetrizes do Município de Sáo Paulo, 1977. Sto Paulo, 1978. (Dissertação de Mestrado Escola de Enfermagem da USP).

4. ORGANIZACION MUNDIAL DE LA SALUD. Continuando la educación de los trabajadores de salud : principios e guiss pan el desarrollo de um sistema. Ginebra, 1982.

5. ORGANIZACION PANAMERICANA DE LA SALUD. Educación continua: guin parn in orgenización de programa de educación continue pare el personal de salud. Washington, 1978.

6. PEREDA, P. M. La educación continua y su aplicación en el sector del abastecimento de aqua y saneamiento. Educ. Mod. Salud, Washington, 16(4): 531.551, 1982. 
7. SANTOS, I. dos \& VIEIRA, C. A. de B. Análise crítica da prática atual de enfermagem no pais. In: CONGRESSO BRASILEIRO DE ENFERMAGEM, 319, Fortaleza, 1979. Anais. Brasilia, Associaçăo Brasileira de Enfermagem, 1979.

8. TORRE MONTEJO, E. et alii. La educación continua em el Ministerio de Salud Pública de Cuba Educ. Méd. Salud. Washington, 12(2): 119-133, 1978. 